ORIGINAL ARTICLE

\title{
Capture-recapture to estimate the number of street children in a city in Brazil
}

\author{
R Q Gurgel, J D C da Fonseca, D Neyra-Castañeda, G V Gill, L E Cuevas
}

Arch Dis Child 2004;89:222-224. doi: 10.1136/adc.2002.023481

See end of article for authors' affiliations ......................

Correspondence to: Dr L E Cuevas, Liverpool School of Tropical Medicine, Pembroke Place, Liverpool L3 5QA, UK;

lcuevas@liv.ac.uk

Accepted 4 July 2003
Background: Street children are an increasing problem in Latin America. It is however difficult to estimate the number of children in the street as this is a highly mobile population.

Aims: To estimate the number of street children in Aracaju, northeast Brazil, and describe the characteristics of this population.

Methods: Three independent lists of street children were constructed from a non-governmental organisation and cross-sectional surveys. The number of street children was estimated using the capture-recapture method. The characteristics of the children were recorded during the surveys.

Results: The estimated number of street children was 1456 . The estimated number of street children before these surveys was 526, although non-official estimates suggested that there was a much larger population. Most street children are male, maintain contact with their families, and are attending school. Children contribute to the family budget a weekly average of $\mathrm{R} \$ 21.2(£ 4.25, € 6.0, \mathrm{US} \$ 7.5)$ for boys and $\mathrm{R} \$ 17.7$ (£3.55, €5.0, US\$6.3) for girls.

Conclusion: Street children of Aracaju have similar characteristics to street children from other cities in Brazil. The capture-recapture method could be a useful method to estimate the size of this highly mobile population. The major advantage of the method is its reproducibility, which makes it more acceptable than estimates from interested parties.
$\mathrm{T}$ he sight of unsupervised and unprotected children is common throughout Latin America, Asia, and Africa. ${ }^{1-3}$ It is estimated that in Brazil alone there are 7-17 million children on the streets. ${ }^{2}{ }^{4}$ This is an enormous problem, the actual size of which is hidden somewhere in a very wide estimate. The truth is, nobody really knows how many they are and worse, nobody knows how to count them..$^{5-7}$ This is not a trivial issue. The number of street children is minimised or inflated to suit the needs of interested parties who receive funds proportionate to the estimated number of children in the streets, and is often a contentious issue. For example, in Aracaju, a city in the northeast of Brazil, estimates vary from "two to three hundred" to "several thousand" children.

Street children often work, ${ }^{89}$ and are under greater danger for abuse and exploitation; the first step to change this situation is to establish how many they are. This study explores the potential of using capture-recapture to estimate the number of street children in a reproducible way. In addition, we describe the characteristics of the children.

\section{METHODS}

We used the capture-recapture method to estimate the number of street children in Aracaju, a middle sized city in northeast Brazil, with a population of $461534 .^{10}{ }^{11}$ This is a technique that has been used in biology to quantify the size of wild animal or insect populations and, more recently, to quantify groups of people who are highly mobile or have restricted access to health services. ${ }^{12-14}$ The method uses incomplete lists of the population to estimate its size and has never been reported within the context of street children. With this method, the size of the lists constructed from separate sources and the frequency of appearance of the children in more than one list are important as these are used to estimate the total population size. ${ }^{13} 14$

We constructed lists of street children from different sources of information. The lists were then checked to identify children who appeared in one or more of the lists.
Three lists were used; the first list was built from the registers of all non-governmental (NGOs) and governmental organisations working with street children in Aracaju, and included all street children that had been in contact with the Fundação Renascer during the year. This is the state's institution responsible for providing care and support to street children in shelters, day and boarding centres, and provides services to around 550 children. Two additional lists were constructed by using cross sectional surveys in the streets. For these, a team of 20 interviewers walked selected streets of the metropolitan area of Aracaju. Streets were selected by asking social workers to identify areas where they had met street children before. The teams visited the streets and recreational areas (for example, beaches and restaurants) during a midweek day and again during a weekend day to construct the second and third lists. Children who stayed in the street during most of the day were selected and were mostly identified by being unaccompanied, idle without an obvious purpose for being in the street, or working (begging, selling, parking cars, etc). Only children below 19 years of age were enrolled as this is the legal age for defining an adult in Brazil. The surveys did not intend to identify all street children, as the method uses the overlap of individuals and lists sizes to estimate the population size. ${ }^{15} 16$ After informed verbal consent of the child, we registered their names, gender, nickname, place of residence and origin, parental names, frequency of family contact, number of nights per week they slept at home, income generation activities, weekly income, and school attendance and performance. At the end of the interview, children were given a chocolate to thank them for their participation.

A database was created using EPINFO 2000. After allowing for spelling errors, children were sorted by name, nickname, sex, and parental names to identify if they were included in one, two, or three lists. The identification was made manually on printed lists. Children with similar names and at least two other matching variables in another list were considered as 
overlaps. Multiple captures of the same child within one list, which occurred when separate interviewers approached the children in different locations, were discarded.

After identifying the overlaps, we used the log linear model for capture-recapture. ${ }^{13}{ }^{14}$ With this model it is possible to use more than two lists to estimate population size, calculate odds ratios, and verify source dependency. The model assumes that the population is not necessarily homogeneous and that the lists are not necessarily independent. After estimating the population size, we described the characteristics of the children participating in the street surveys.

Ethical approval for the study was obtained from the Liverpool School of Tropical Medicine (UK) and the University of Sergipe ethics committees.

\section{RESULTS}

The Fundação Renascer had 526 children registered; each street survey identified 257 and 295 children respectively. Figure 1 shows the number of children appearing in more than one or more lists. Using these figures for the log linear model equation, the estimated number of street children in Aracaju is 1456.

The street surveys identified a total of 520 children. The majority of them were male $(438,84 \%)$ and were between 10 and 15 years of age, with the youngest being a 1 year old girl living in the street with her mother. Girls were younger than boys, with a mean (SD) age of 9.4 (3.7) years and 12.2 (3.5) years respectively $(\mathrm{p}<0.001)$. Most children had been born in Aracaju $(338,65 \%)$, although a relatively large proportion $(182,35 \%)$ had migrated from rural areas and other states such as Bahia, Alagoas, Pernambuco, and São Paulo, hundreds of miles way. Remarkably, the majority of children were still attending the local schools $(301,57.6 \%)$ and spent part of their time working in the streets. Most children had contact with their biological parents and $94 \%$ slept at home at least once a week. Children slept a mean (SD) of 3.2 (1.02) nights a week outside their homes.

Table 1 shows the occupations most frequently identified for boys and girls. Boys were often begging, invigilating cars, cleaning shoes, selling small goods, and carrying market goods. Only a small proportion of children reported involvement in criminal activities. This was, however, likely to be underreported given that the interview took place in the street. Girls had less diverse activities and most of them were either begging or selling goods. Most children reported making an income from these activities; girls made a mean of R\$17.7 ( $€ 3.55, € 5.0$, US\$6.3) while boys made $\mathrm{R} \$ 21.2$ $(£ 4.25, € 6.0$, US\$7.5) $(p=0.07)$. Half of the children indicated that they had an income above $\mathrm{R} \$ 15$ per week

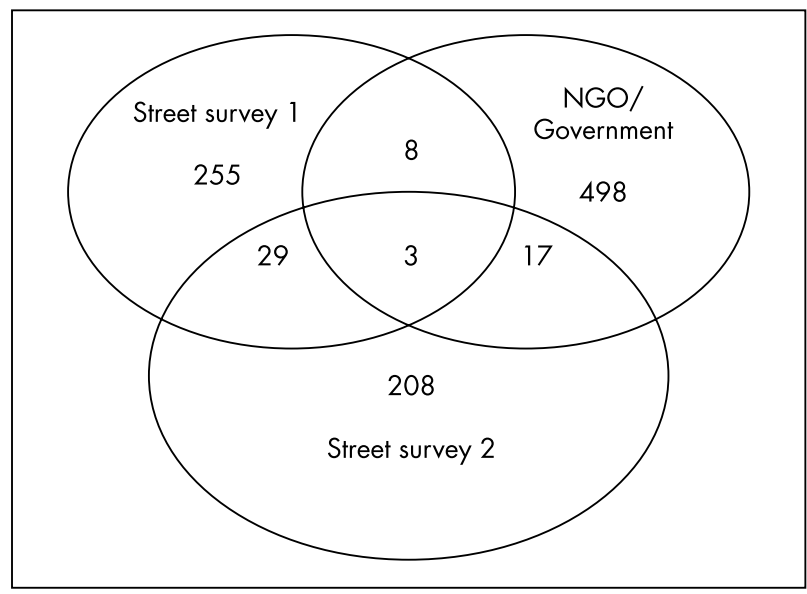

Figure 1 Number of children appearing in each list.
Table 1 Street children stratified by sex and activity

\begin{tabular}{|c|c|c|c|c|}
\hline \multirow[b]{2}{*}{ Main activity } & \multicolumn{2}{|c|}{ Boys } & \multicolumn{2}{|c|}{ Girls } \\
\hline & $\mathbf{n}$ & (\%) & & (\%) \\
\hline Shoe cleaner & 53 & (12.1) & 2 & (2.6) \\
\hline Begging & 147 & (33.6) & 48 & (58.4) \\
\hline Car cleaner & 147 & (32.6) & 11 & (13.0) \\
\hline Selling small goods & 43 & $(9.8)$ & 17 & (20.8) \\
\hline Carrying market goods & 50 & (11.4) & 4 & (5.2) \\
\hline Criminal activities* & 2 & (0.5) & - & $(0.0)$ \\
\hline Total & 438 & $(100)$ & 82 & $(100)$ \\
\hline
\end{tabular}

( $£ 3.00)$, which is more than four times the R\$15 per month paid by the new Brazilian Scholarship Program. Children attending school reported a similar income to that of those not attending ( $R \$ 21.00$ and $R \$ 20.27$ respectively).

\section{DISCUSSION}

Street children in Aracaju have similar characteristics to those of most street children described from other Brazilian and Latin American cities, ${ }^{4-6}$ with the majority being male, maintaining family contact, and generating an income that is often crucial for the maintenance of siblings and-oftenunemployed parents. The majority of children return home at night and most of them are in the streets to generate income for themselves and the family. ${ }^{17}$ Although we did not investigate whether income generation is a factor that pushes these children to the streets, it is likely that this income is crucial for the family budget as most parents receive money from their children. ${ }^{18}$ It is important that the average income of these children is higher than the government scholarship programme. These scholarships aim to encourage and support children to stay in school, but might be unlikely to succeed if the expectation of the parents is that the scholarships would replace the income generated by their children.

Almost all reports indicate a clear gender imbalance in street children; between $75 \%$ and $90 \%$ of Latin American and African street children are male. ${ }^{1-5} 8$ The causes of this imbalance, however have rarely been investigated. Whether this reflects the cultural perception that it is more dangerous or less acceptable for girls to go to the street or that boys function under a different set of influences and factors, is uncertain. ${ }^{18}{ }^{19}$ We interviewed children in the street and could not explore the proportion of female street children who had suffered physical or sexual abuse. Their situation, however, clearly needs to be the focus of future research.

The capture-recapture technique has been used in populations that are difficult to quantify by routine surveillance or where conventional surveys are likely to encounter significant shortcomings. ${ }^{12-15} 2021$ Street children have high social and health risks, are exposed to occupational hazards, street violence, and accidents, and are susceptible to be induced to use drugs and engage in prostitution. ${ }^{18}$ These children, however, avoid contact with government or official institutions and it is difficult to ascertain their numbers. The technique could be suitable to estimate the size of this population in a way that is standardised and reproducible. While the government recognises that the phenomenon of street children is important, it estimates that there are a few hundred of them in the streets, with between 200 and 500 children often quoted in their documents. NGOs on the other hand estimate that the number is much higher, with around 2000-3000 children.

It is thus important to discuss whether 1456 is the real number of street children, as other authors have indicated 
that this method has produced unreliable results in other situations. ${ }^{22}$ Although it is likely that the real figure lies somewhere between 200 and 3000 , the former is likely to be an underestimate, as funding agencies tend to deflate numbers to protect limited resources, and the second is likely to be an overestimate, as it is well known that NGOs inflate numbers to secure financial support. Up until now, however, there is no accepted method to estimate their number using a technique that can be scrutinised and-if wanted-criticised. Capture-recapture seems able to estimate the approximate size of the street children population in a fashion that is reproducible and less vulnerable to external manipulation. These two latter characteristics, reproducibility and independence from external manipulation, might be the most important and critical issue; perhaps more important than whether this number is similar to estimates obtained with other (non-existent) gold standards.

\section{Authors' affiliations}

R Q Gurgel, J D C da Fonseca, Nucleus for Postgraduate Medicine, Federal University of Sergipe (UFS), Aracaju, Sergipe, Brazil D Neyra-Castañeda, Department of Statistics, UFS, Aracaju, Sergipe, Brazil

G V Gill, L E Cuevas, Liverpool School of Tropical Medicine, Liverpool, UK

Funding: the study received funding from FAP-SE (Sergipe research support grants), grant number "edital 01/2001". JdelCF received a research scholarship from the Federal University of Sergipe (PIBIC/ CNPq/UFS-(JDCF))

\section{REFERENCES}

1 Aptekar L. Street children in the developing world: a review of their condition. Cross-cultural Research 1994;28:195-224.

2 Rosemberg F. Estimativas de Crianças e Adolescentes de Rua na Cidade de São Paulo. Cadernos de Pesquisa-Fundação Carlos Chagas 1994;91:30-45.
3 UNICEF, United Nations Children's Fund. The state of world's children. Oxford: Oxford University Press, 1993.

4 Silva A, Reppold C, Santos C, et al. Crianças em situação de Rua em Porto Alegre: um estudo descritivo. Psicologia: Reflexão e Crítica 1998;1 1:441-7.

5 Aptekar L. Characteristics of street children in Colombia. Child Abuse Negl 1989;13:427-37.

6 Rizzini I. Street children: an excluded generation in Latin America. Childhood 1996;3:215-33.

7 Rosemberg F. Estimativas de Crianças e Adolescentes em Situação de Rua: procedimentos de uma pesquisa. Psicologia: Reflexão e Crítica 1996;9:21-57.

8 Lowry C. Street children in the developing world, Canadian International Development Agency, Mimeo, 1997.

9 Ennew J. Street and working children. A guide to planning. Development manual 4. Save the Children Fund, UK, 1994.

10 IBGE. Instituto Brasileiro de Geografia e Estatística. Censo 2000. Rio de Janeiro: IBGE, 2002.

11 França VLA. Aracaju: Estado e Metropolização. First edition. São Cristóvão (SE). Federal University of Sergipe, 1999.

12 La Porte RE. Assessing the human condition: capture-recapture techniques. BMJ 1988;308:5-6.

13 La Porte RE, McCarty DJ, Tull ES, et al. Counting birds, bees, and NCDs. Lancet 1992:339:494-5.

14 International Working Group for Disease Monitoring and Forecasting. Capture- recapture and multiple-record system estimations II: Applications in human diseases. Am J Epidemiol 1995; 142:1059-68.

15 Fisher N, Turner SW, Pugh R, et al. Estimating numbers of homeless and homeless mentally ill people in north east Westminster by using capturerecapture analysis. BMJ 1994;308:27-30.

16 Watts C, ZWI A, Foster G. How to do (or not to do)... Using capture-recapture in promoting public health. Health Policy Plan 1995; 10:198-203.

17 UNICEF, United Nations Children's Fund. Latin America Seminar on Community Alternatives for Street Children, Brazilia, 1984:12-15.

18 Shinkafi Z, Gurgel RQ, Brabin BJ, et al. The characteristics of street children of Aracaju, Sergipe. Submitted.

19 Raffaelli M, Koller SH, Reppold CT, et al. Gender differences in Brazilian street youth's family circumstances and experiences on the street. Child Abuse Negl 2000;24:1431-41.

20 Gill G, Scott B, Beeching N, et al. Enumeration of non-communicable disease in rural South Africa by electronic data linkage and capture-recapture techniques. Trop Med Int Health 2001;6:435-41.

21 Yadón Z, Quigley M, Davies C, et al. Assessment of leishmaniasis notification system in Santiago del Estero, Argentina, 1990-1993. Am J Trop Med Hyg $2001 ; 65: 27-30$.

22 Tilling K. Capture-recapture methods-useful or misleading? Int J Epidemiol 2001;30:12-14. 